\title{
Winckelmann e o sem fim
}

\author{
Pedro Fernandes Galé - USP
}

\begin{abstract}
Filtrarei um dia os séculos / Que se acumulam no olhar / Até que a pedra suspire / Os segredos da atmosfera. Murilo Mendes "Aerograma" As metamorfoses
\end{abstract}

Goethe, em seu texto "Shakespeare e o sem fim", fez uma perspicaz colocação sobre o poeta inglês: "Ele é, se considerado mais de perto, um poeta decididamente moderno, separado dos antigos por um precipício monstruoso, e não segundo a forma exterior, aqui deixada de lado, mas segundo o sentido mais íntimo e profundo". (Goethe, 2000, pp. 33-34). Não se trata aqui, de modo algum, de fazermos uma comparação entre Winckelmann e o autor de Hamlet, mas de pensarmos essa modernidade, não meramente formal e que se dá num tipo de produção que ainda não é vinculada ao que chamamos de romântico ${ }^{1}$. Posto que

${ }^{1}$ Embora, segundo Giuli Preti, em sua tradução de Schelling, Le arti figurative e la natura, de 1945, haja um vínculo claro entre Winckelmann e os românticos: "Mais que a influência da estética sistemática, que estava a nascer na Alemanha como obra de Baumgarten, Winckelmann sente a viva influência de Shaftesbury, cujas ideias se adaptavam melhor àquela experiência artística profundamente nova que caracterizavam as posições de 
Shakespeare "não é um desses poetas a que chamamos românticos" (Ibid.), no trato com nosso autor podemos retomar aquilo que Goethe diz sobre o poeta: "Ele pertence muito mais àquele gênero a que chamamos ingênuo (...) aproximando-se da nostalgia apenas em pontos extremos". (ibId.).

Esse lugar especial, que permite que se seja moderno e ao mesmo tempo ingênuo ${ }^{2}$ é o que podemos considerar um dos móbiles do sem fim de Shakespeare no texto de Goethe. Sem grande esforço poderíamos aplicar também ao sem fim de Winckelmann. A chave da nostalgia, embora não seja, aqui objeto de discussão mais ampla, não é a melhor via para compreendermos Winckelmann. Ele não é nostálgico, embora um de seus estudiosos mais interessantes, Fausto Testa, tenha dito que para o autor de História da arte da antiguidade "o clássico se aprofunda em uma distância infinita, não restando dele mais do que a sombra e a nostalgia" (Testa, 1999, p. 344). Diante deste abismo que nos separa do antigo, o melhor caminho para compreendermos Winckelmann é o de uma relação viva com este lugar histórico determinado. Nos dizeres de Walter Pater, em seu O renascimento: "Winckelmann detém a chave para o entendimento do espírito grego em sua própria natureza, ela mesma uma relíquia

Winckelmann no seio da cultura europeia, e faz dele, em plena idade das luzes, o primeiro dos românticos" ( $O p$. cit, p. 14). Embora não concordemos com tal qualificação, ela não deixa de mostrar as dificuldades de se encerrar Winckelmann em um posto determinado.

2 Nos dizeres de Schiller: "Todo verdadeiro gênio tem de ser ingênuo ou não é gênio. (...) O gênio tem de solucionar as tarefas mais complexas com despretensiosa simplicidade e desembaraço; o ovo de Colombo vale para toda decisão genial. Legitima-se como gênio somente por triunfar com simplicidade sobre a arte complexa. Não procede segundo princípios conhecidos, mas segundo inspirações e sentimentos; suas inspirações são estros de um deus (tudo que a natureza faz é divino), e seus sentimentos são leis para todos os tempos. (Schiller, 1991, p. 51) 
da antiguidade clássica aberta por acaso a nossa atmosfera moderna." (Pater, 2014, p. 207). Essa chave de ter a Grécia em seu espírito fez com que se pudesse observar o substrato material remanescente; mais do que uma estatuária impressa em pedra morta, os gregos permanecem, de algum modo, vivos em suas obras. A via para a apreensão deste mundo, ainda que de modo parcial, pode ser encontrada; permitindo uma declaração como: "O único caminho para que nos tornemos grandes e, quando possível, até mesmo inimitáveis é a imitação dos antigos" (Winckelmann, 2002, p. 31).

A posição peculiar deste autor, anterior, segundo Goethe, aos "acontecimentos dos novos tempos" (Goethe, 1969, p. 225), ou seja, às duas revoluções, a copernicana, empreendida por Kant e a francesa, nos permite pensar um esforço que não termina, um impulso em relação à antiguidade artística e ao trato com as artes que traz em si a sua carga de modernidade: "Talvez seja preciso ser arquimoderno para ter um ponto de vista transcendental sobre a antiguidade. Winckelmann sentiu os gregos como um grego" (Schlegel, 1997, p. 95), dizia o romântico August Schlegel. Portanto, para o autor da Kunstlehere, Winckelmann poderia não ter sido moderno o suficiente para que pudesse superar a experiência viva dos gregos no sentido de uma depuração que se afastasse do objeto particularizado, o que poderia ser entendido como uma espécie de conhecimento transcendental. Se pensarmos na própria caracterização do que seria o conhecimento transcendental dada por Kant não será difícil compreender que o autor de História da arte da antiguidade realmente não se encontra plenamente em tal registro: "Chamo transcendental todo o conhecimento que em geral se ocupa menos dos objetos, que do nosso modo de conhecer, na medida em que este 
deve ser possível a priori" (Kant, 1997, p. 53).

Ao tomarmos essa definição do transcendental, não se torna difícil entender que Winckelmann, grego ou não, fique um tanto quanto distante de tal abordagem e mais ainda do caráter arquimoderno. Em sua obra os objetos são a parte central do trabalho, eles não são exemplos de uma teoria, mas elementos constituintes dessa teoria. Embora haja, de certo modo, uma preocupação em relação ao modo de conhecer os objetos: "a capacidade de sentir o belo na arte é um conceito que une a um só tempo a pessoa e a coisa, ou seja, o contentor e o conteúdo, o que eu, portanto, encerro em uma unidade." (Winckelmann, 2002, p. 212). Esse aspecto fundamental elimina a possibilidade de uma apreciação das artes que seja passiva ou mera recepção inativa. O lugar desta atividade da sensibilidade é posto pela união do sujeito que observa e a obra de arte bela e ambos são apresentados como que a um só tempo e de modo inseparável. Portanto, por mais que se busque compreender o "sentimento do belo" ele não é passível de isolamentos em relação ao seu objeto.

A presencialidade da obra será um dos postulados mais caros a Winckelmann e talvez o único postulado central de sua teoria já presente em seu primeiro escrito, não publicado em vida, (onde ele, de modo quase oposto ao que veremos em seus textos posteriores, se colocava como simpatizante da pintura holandesa e de Craravaggio $^{3}$ ) as Descrições das principais pinturas

${ }^{3}$ Para ilustrar essa peculiaridade, que nos baste as seguintes passagens: "Eles [os Carracci] têm um modo escuro de pintar, para o qual há objeções desde sua época. (...) Essa escuridão deve ser diferenciada da força e da audácia de Caravaggio." (Winckelmann, 2007, p. 6). E quando fala de Guercino, Guido Reni e Albani, no que se refere à luz ele declara: "Falta algo em suas obras, algo que pode ser encontrado nas obras de Correggio, Rubens, van Dyck, Rembrandt e de quase todos bons pintores holandeses. 
da galeria de Dresden": "Pergunte a um filósofo da antiguidade: o que é a beleza? Eu falo com referência a Aristóteles, deixe essa pergunta para os cegos, ele diria. Venha e veja." (Ibid., p. 8). E "essa máxima retomada do evangelho toma a consciência certeira da inelutável necessidade de uma contemplação direta para encontrar o caminho da compreensão da arte, e é por meio de uma citação do evangelho, o 'venha e veja' de São João (I,47), que se exprime a sua concepção." (Pommier, 2003, p. 29).

A insistência no ver marcará toda a teoria de Winckelmann; é da percepção que se parte, mas ela não encerra o processo. Tal presencialidade é na verdade uma cláusula sine qua non de toda experiência, por falta de termo melhor, estética. O duplo influxo desta experiência é uma característica fundamental do modo de ver as artes deste autor. Somente da união entre esses aspectos, ou seja, o olho e a obra, é que a capacidade de sentir o belo pode ser formada: "Acontece com esta capacidade o mesmo que com o universal entendimento sadio, todos acreditam possuí-la, e esta é ainda mais rara que o engenho $(\text { Witz })^{5}$,

Deixo isso para que vejas, não para que se fale." (Ibid. 7).

${ }^{4}$ Beschreibung der vorzüglischsten Gemälde der Dresdner Galerie. Texto escrito no final de 1752 quando Winckelmann trabalhava em Nöthnitz como Bibliotecário para o Conde de Büneau. Vale destacar que neste momento o quadro que viria a ser a Prima Donna desta coleção, a Madona Sistina, de Rafael, ainda não havia sido adquirida.

${ }^{5}$ Apesar de o termo Witz poder ser traduzido por chiste, como o fez Márcio Suzuki, acreditamos que aqui se refira a outra tradução possível, pois Winckelmann parece se inserir em um léxico cujo contexto é mais Leibniziano (Christhian Wollf definiu o chiste como "facilidade de perceber semelhanças"; Wolff, apud. Suzuki, 1998, p. 197, nota 28) , a frase lida com a acepção que o próprio Márcio Suzuki sugere: um termo que ainda se vê carregado da "ressonância filosófica da palavra em alemão, onde corresponde ao francês esprit, ao inglês wit e ao latim ingenium (o que tornaria plausível a tradução por engenho em português)." (Suzuki, 1998, p. 197, nota 28). 
posto que todos possuem olhos, todos acreditam poder ver como os outros" (Winckelmann, 2002, p. 213). O que não significa que o arbítrio e a subjetividade devam suprir as diferenças e preencher qualquer sorte de lacuna pois "o céu deu a todas as criaturas racionais a capacidade do sentimento do belo, mas em grau muito diverso" (Ibid.). Embora haja uma série de diferenças possíveis, o substrato sobre o qual repousa tal capacidade é dado a todos os homens e se desenvolve a partir dos objetos.

Mas a própria atividade do sujeito não se dá de modo unitário. O ver se desdobra, o sentimento do belo coloca em operação duas espécies de sentidos, o interno e o externo: "O aparato deste sentimento é o sentido externo e sua sede é o sentido interno. O primeiro deve ser exato e o segundo deve ser sensível e delicado" (ibid., p. 217). Este duplo atuar de nossas percepções coloca o trajeto em relação às belezas de modo a não ter fim. A exatidão do olho e a delicadeza do espírito são características em constante formação e educação. Tal educação se dá diante dos objetos vistos:

Se o sentido externo é justo, podemos inferir que o interno seja, portanto, perfeito, pois este é um segundo espelho no qual podemos ver o essencial de nossa semelhança através do perfil. O sentido interno é a representação e a formação das impressões do sentido externo; para dizer em poucas palavras: é aquilo que chamamos sentimento. O sentido interno, todavia, não é

Embora aqui a ressonância da concepção que leva à tradução por chiste também se apresente, pois quem duvida da raridade de se obter sucesso em um chiste, gracejo ou piada? Podemos pensar também que Winckelmann joga com a acepção de vário tipo da palavra em alemão. 
sempre proporcionado pelo externo, ou seja, a sensibilidade do primeiro não corresponde em grau à exatidão do outro, pois o sentido externo é mecânico em suas ações, ao passo que o interno é espiritual. (Ibid., p. 218)

Esse duplo atuar do sujeito proporciona um tipo de movimento que é constante e interminável. E isso não se dá por uma exigência individual e subjetiva, há uma sorte de fundamento objetivo na própria capacitação destes sentidos. O que se espera é que o espectador se eduque em conformidade aos seus objetos: "Esta capacidade [a de sentir o belo] será excitada e aparecerá mais cedo por meio da boa educação" (Ibid., p. 215). Ela exige um trajeto:

Primeiro este coração e este sentimento devem ser movidos e excitados pelo esclarescimento dos mais belos pontos dos antigos e novos escritores, principalmente os poetas. E com isso sua própria consideração da beleza de toda sorte será preparada, pois este caminho conduz à totalidade. Ao mesmo tempo este mesmo olho deve se habituar à observação do belo na arte que pode ocorrer apenas de modo precário em diversos países.(Ibid., p. 221)

Essa proposta é quase que pedagógica e segue num sentido em que se possa educar o olho ao belo em qualquer lugar do globo; mesmo que se trate de um lugar como sua cidade natal, Stendal, ao norte de Brandemburgo. O educar-se à beleza é dado de um 
modo em que a sua fonte não plástica, a poesia, faça com que a totalidade se apresente como característica da imaginação que observa. Trata-se de uma educação do sentido interno, que vai se tornando mais refinado e mais sensível. O ideal de Winckelmann é uma espécie de atividade estética universal alcançável por todos os seres humanos. O que não significa uma afirmação irrestrita da autonomia do sujeito, posto que todos os que experimentam essa relação com a beleza devem se submeter a ela: "o todo da teoria parece querer agora 'formar o bom gosto', restaurar um conceito de beleza objetivo e universal, fixar um horizonte normativo que contraste a anárquica arbitrariedade do gosto subjetivo." (Testa, 1999, p. 128).

A educação não parte de uma relativização subjetiva do gosto, embora o que se pretenda nesta investigação da capacidade do sentimento do belo ${ }^{6}$ seja estabelecer uma via para a beleza que estabelecesse no sujeito a capacidade de sentir o belo. A universalidade do belo se impõe, mesmo que sob a via da comunicabilidade universal, ou seja, estamos diante de um viés individual, mas que é universalmente reconhecível. A educação garantiria o alcance de tal capacidade a todos os indivíduos possíveis, posto que a todos foi dada, ao menos potencialmente, tal capacidade; o trabalho, portanto, seria desenvolvê-la: "essa capacidade da qual falamos deve ser treinada desde cedo e conduzida pelo belo antes que se chegue a uma idade na qual nos espantamos em confessar que não o sentimos" (ibid., p. 216).

O que se espera é que o sujeito se eduque de acordo com os objetos vistos, o particular deve se colocar em íntima relação

${ }^{6}$ Abhandlung von der Fahigkeit der Empfindung des Schönen in der Kunst, und dem Unterrichte in derselben ["Ensaio sobre a capacidade do sentimento do belo na arte e do ensinamento da mesma"] . 
com o sujeito para que a universalidade do belo tenha lugar. Aquilo que se encontra plasmado nas obras é que permite o duplo atuar e a educação desses sentidos. Mas este sujeito em formação cobra por um objeto, e este objeto deve ter sua carga de idealidade. Tomemos o exemplo mais caro a Winckelmann, o Apolo de Belvedere:

A contemplação desta maravilha da arte me faz esquecer todo o resto. Eu mesmo procuro adotar uma postura digna para admirar tal obra do modo que ela merece. (...) E me parece que o objeto de minha contemplação, como o de Pigmalião, cobra vida e movimento. Como pintá-lo, como descrevê-lo? Teria de ser guiado pelas mãos das artes para dar conta do que comecei a esboçar aqui. Só me resta ofertar aos pés da estátua os conceitos dela extraídos e aqui esboçados, tal qual a coroa dos que decidem cingir as cabeças dos deuses e não as podem alcançar. (Winckelmann, 2009, p. 780).

O que podemos notar é que mesmo um todo aparentemente encerrado e delimitado como o Apolo de Belvedere traz a carga do movimento sem fim da experiência estética. Ainda que, segundo Winckelmann, o observador possa, diante desta obra, ser "elevado ao reino das belezas incorpóreas e intente ser criador de uma natureza celestial para encher seu espírito de belezas que se elevam por sobre a natureza" (Ibid.), não há como o receptáculo humano poder encerrar tal atividade. Este voo na direção do imaterial é um caminho que não tem fim. Análogo às obras, 
o observador deve tentar se elevar para além da materialidade, ou, "tomar da materialidade apenas o necessário" (Ibid.).

Há um principio que gira em torno da economia expressiva dos gestos, das ações e das caracterizações; o ideal aqui é o da arte que é moderada em sua expressão: "O Platão da Escola [de Atenas] de Rafael move apenas o dedo e nos diz muito; (...) assim como é mais difícil indicar muito com pouco do que o contrário, o entendimento justo prefere o fazer com pouco ao fazer com muito, de tal modo uma única figura pode ser o teatro de toda maestria de um artista" (Id., 2002, p. 149-150). A própria escolha da escultura parece promover esse ideal de economia que não deixa de revelar a sua duplicidade. À pergunta acerca da centralidade da escultura em Winckelmann, respondeu Walter Pater: "Porque, por essa limitação, ela se torna um meio de expressão perfeito para um motivo intelectual do intelecto imaginativo. Por isso, ela renuncia a todos os atributos do seu material que não promova aquele motivo." (Pater, 2014, p. 201).

A duplicidade, presente no observador, também encontra o seu correlato na obra de arte. Há na própria obra algo que de antemão se apresente aos dois sentidos, interno e externo, ela fornece sua faceta material (mecânica) e a sua faceta espiritual. $\mathrm{O}$ aspecto que as une é a própria sabedoria artística. E o observador treinado poderá cada vez mais sentir e ver a faceta espiritual e universal no caso particular, mas não se pode abandonar aquilo que se configura como materialmente plasmado na obra. É na própria materialidade, econômica, da obra que a beleza pode ser apresentada aos nossos olhos. O ideal mais elevado e puro de beleza, em última análise, não seria sequer passível de figuração: "a beleza suprema reside em Deus e o conceito que 
podemos formar da beleza humana será tão mais perfeito se se conformar e concordar com o Ser Supremo, que nosso conceito de unidade e indivisibilidade nos permite discernir da matéria" (Winckelmann, 2009, p. 250). Tal beleza é quase que uma idéia reguladora e não se apresenta aos homens senão em sua faceta corruptível e material; posto que suas características são indissociáveis da imaterialidade, ela permanece como um aspecto que norteia a produção artística.

Aquilo que vemos numa obra de arte nunca é essa beleza unitária e indivisível de que nos fala Winckelmann em sua História da arte da antiguidade. A beleza artística se apresenta sempre inserida no mundo do devir, do vir a ser. É na superação da materialidade que reside o esforço sem fim do artista. Esforço para se alcançar " um grande entendimento que pôde se elevar por sobre a matéria" e "uma mão que foi conduzida e determinada pela formação da mais elevada essência" (Id., 2002, p. 275). Uma imposição análoga é posta àquele que busca entender a beleza e, como no caso do artista e do espectador, a atividade não se encerra:

Os sábios que pensaram sobre a fonte do belo em geral, que o investigaram em coisas criadas e trataram de chegar à fonte da beleza suprema, acreditaram no perfeito coincidir da criatura com seus desígnios e suas partes constituintes. Mas isto equivaleria à perfeição, da qual o ser humano não poderia ser um receptáculo com capacidade suficiente; nosso conceito universal da beleza permanece indeterminado e se forma em nós por conhecimentos soltos que unimos e ligamos e que, se corretos, nos apresentam o mais alto grau da 
beleza humana, a qual elevamos por sobre a matéria. (id, 2009, p. 250)

É na superação da materialidade que devemos empreender nossos esforços no âmbito da conceitualidade do belo em geral. Mas esta beleza, a partir do momento em que se vê plasmada, se vê infundida da corruptibilidade da matéria e é no equilíbrio entre essa imaterialidade e a própria materialidade, no sentido de uma determinação recíproca, que se pode observar a beleza ideal. É nesse sentido que uma obra como o Apolo de Belvedere nos lança na direção do insondável pois ele "representa o supremo ideal das artes, o artista tomou não mais que o imprescindível da matéria para realizar e tornar clara sua intenção. (...) Sua figura é superior à humana e sua atitude reflete a grandeza que se vê encerrada." (Id., 2002, p. 267)

Essa grandeza sobre humana não é o resultado corrente das obras de arte em geral, mas algo que se atinge na boa relação da materialidade com a incoporeidade. A matéria se torna receptáculo para o imaterial. E sem fim é o esforço do espectador no sentido de poder captar essa beleza singular que descende do que há de mais elevado para diante dos nossos olhos. Como já dissemos, olho deve ser treinado a partir de tal sorte de objetos. E, assim como em seu texto primevo sobre a Galeria de Dresden, sua máxima permanece, juntamente com o sem fim de toda a atividade especulativa: "A mais elevada clareza não pode ser dada em coisas que repousam sobre os sentimentos, e aqui não é permitido que se professe tudo de modo escrito. (...) Aqui se diz: vá lá e veja." (Ibid., p. 233)

Mas tal observar não se dá de modo estático. Embora da obra irradiem conceitos e aspectos que podem ser apreendidos 
pelo observador, a atividade é de um perpétuo mover-se,

Pois o belo e o útil não podem ser captados de uma só vez. (...) O importante e o decisivo exigem maior profundidade e não afloram da superfície. Para todos os que possuem sensibilidade, a primeira visão de uma bela estátua é como a primeira contemplação do mar aberto, na qual nossa visão se perde e se paralisa. Contudo, com a contemplação repetida o espírito se torna sereno e os olhos ficam tranquilos; passando de uma visão do todo ao detalhe. (Id., 2009, 558).

Esse constante visitar é o que nos permite superar a superfície; é esse mergulho que nos leva às profundezas imateriais da obra plasmada. Um caso exemplar de tal contemplação profunda, ou seja, de uma observação que transpõe a superfície da obra e que se faz de um modo também ativo pelo espectador é a descrição que fez Winckelmann do Torso de Belvedere. Essa descrição é quase que um análogo do todo de sua obra de e demonstra como poucas passagens o sem fim intrínseco à atividade de reconstituição e atualização do mundo grego. Para tratar dessa peça "sem braços, pernas e cabeça [que] recebeu grande fama e atenção de todo artista de entendimento afiado graças à sua grande beleza" (Id., 1995, p. 167), o que se pode fazer é uma abordagem que se projete para além da fragmentada estátua materialmente colocada.

O olho do espírito terá de se elevar o quanto possa por sobre as lacunas materiais e superá-las em discurso: "essa descrição se refere unicamente ao ideal desta estátua, especialmente onde ela é ideal" (ibid., p. 174). A descrição como um todo terá 
de ser ideal como atesta o final do texto: "após essa descrição ideal se deve seguir uma sobre a arte" (ibid., p. 180). Posto que a própria peça se encontra em um estado lacunar, "como posso descrevê-lo se se encontra privado das mais significantes partes da natureza?" (ibid., p. 175). Essa descrição não é a mera transposição da imagem para o discurso, ela coloca uma questão que nos podemos colocar em relação a toda antiguidade, nós nos encontramos no "precipício monstruoso" que nos separa dos antigos, um lugar onde nos falta muito mais do que gostaríamos. Essa descrição, por vários motivos, se coloca para além da ekphrasis antiga; ela é como que "uma prova de tudo que se pode pensar sobre uma obra de arte de tamanha perfeição e também exemplo de um inquérito no campo artístico" (Ibid.). A imagem ideal, disponível apenas aos delicados mecanismos do sentido interno, vai sendo construída discursivamente a partir de um fragmento.

Este caminho onde o sentido interno e o sentido externo se unem, ou seja, o caminho que une olho e espírito, leva o espectador a ver "mesmo um milagre" (Ibid., p. 170). Pois onde "à primeira vista não víamos mais do que uma pedra disforme" (Ibid.), com o auxílio do espírito, passaremos ver "Hércules como que em toda a sua ação, e o deus e o herói se farão visíveis ao mesmo tempo nesta peça." (ibid.). Contra a própria materialidade, nossos olhos se transfeririam a um ideal que surge a partir da soma de duas dualidades: a dualidade dos sentidos e a dualidade da própria obra que traz sua carga de idealidade para além de sua superfície. "Por meio de uma arte secreta poderá o espírito desvelar desde todos os feitos de sua força até a completude de sua alma" (Ibid., p. 172). Há uma exigência de que o espírito atue para que se possa sentir o todo da obra. 
Esse espírito se move no sentido de abarcar uma ausência, preencher, ainda que somente na alma, tais lacunas. Este sentido interno, se preparado e educado para apreender perfeições, vai poder preencher pouco a pouco os vazios de modo a dar uma unidade às diferentes presenças que atuam no jogo de completar essa estátua.

A descrição, aqui, "atendendo ao ideal, se resolve finalmente numa espécie de mitologia estética de mediação e superação" (Mas, in Winckelmann, 2007, p. 49). A própria ausência material é que de certo modo traduz e concentra a grandeza do projeto de Winckelmann. Na ausência dos objetos, ou de sua integralidade, o que vem ao auxílio é uma espécie de discurso ideal que se lança para além do que se apresenta aos sentidos. É por meio de tal relação com o ideal que podemos anexar a este torso "uma cabeça cheia de majestade e sabedoria", "os braços que estrangularam o leão no monte Citerão" e "as pernas que perseguiram e alcançaram o cervo de patas de ferro" (Winckelmann, 1995, p. 172). O olho se vê lançado então por sobre o receptáculo material, mas não numa ascensão que eleve os olhos na direção do vazio, mas num salto em que o espírito, munido de um ferramental específico perpassado e afetado pela materialidade reveladora da obra, se permita lançar-se para dentro daquilo que a superfície do mármore estabelecia como puro objeto do ver. O olho deve buscar, com o espírito, o imaterial e espiritual na obra para o qual "a forma (Gestalt) é mero receptáculo" (ibid.). Somente assim poderemos ver no torso um corpo para o qual "o artista deu um nobre ideal, que se eleva por sobre a natureza. A natureza masculina em seus anos de plenitude é ascendida ao grau de serenidade divina" (id., 2009, p. 714).

O artista pôde alçar-se na direção das belezas que não são 
corruptíveis e que trazem em si uma carga quase que divina, ainda que esta tarefa nunca se cumpra em sua plenitude. Neste corpo não vemos sequer uma veia e, sentido internamente em nosso espírito, não é um corpo inserido no devir, no mundo terreno, ele emana uma unidade que se destaca da corrupção mundana. Ele "goza de plenitude e não de saciedade" ele é "feito para o regozijo e não para a nutrição" (Ibid.). Ele é um todo, uma totalidade, que só percebemos se nos debruçamos na matéria plasmada para que aquilo que se vê figurado e sua representação se confundam. Mas não nos confundamos, ainda que o espírito tenha um papel fundamental, o arbítrio individual não será o caminho.

Nessa reconstrução não podemos perder de vista a beleza, que é universal, mas não pode ser compreendida:

A beleza é um dos maiores segredos da natureza, cujo efeito todos vemos e sentimos, mas de sua essência não possuímos um conceito universal significativo, ela pertence às verdades não desveladas. Fosse esse conceito de uma claridade geométrica, o juízo dos homens sobre o belo não seria tão diverso e seria fácil que por si a verdadeira beleza convencesse os homens." (Id., 2009, p. 240).

Posto que não existe uma norma dedutível de princípios gerais, como reconhecer a beleza? A resposta pode parecer até simplória: no trato com as obras de arte. O "vá e veja" é que vai permitir que se se eduquem os juízos. Os juízos baseados em pré-julgamentos serão sempre perniciosos. O arbítrio individual não é um caminho, temos de nos mover na direção do 
ideal de beleza plasmado em um lugar histórico. Este lugar foi a Grécia antiga. E a atividade na esteira de uma distinção da beleza artística passa necessariamente pela possibilidade de uma vivência com as obras gregas. Como o movimento estético de Winckelmann não é passível de isolamentos, para que se opere este ferramental do sujeito em direção à objetividade há sempre a exigência da presencialidade das obras; é a partir delas que a movimentação dos modos de perceber vai permitir a extração dos conceitos que aproximam o observador da fruição mais plena possível, mas a atividade não se encerra. Tudo se baseia num constante visitar e revisitar em relação às obras, principalmente as obras dos gregos:

Aquilo que se diz de Homero, que aquele que aprende a se encantar com ele é aquele que o entende como um todo, também ocorre nas obras de arte dos antigos, principalmente dos gregos. Devemos torná-las conhecidas como um amigo para que o Laocoonte seja visto como tão inimitável quanto Homero. (Id., 2002, p. 31)

Esse caminho não é apenas o caminho do artista, todo aquele que quer conhecer a arte deve conhecer seus frutos com uma dedicação semelhante à de um amigo. É no trato com tais obras que a beleza artística vai poder se revelar. Ela está expressa nas obras dos gregos e tal aproximação nos permitiria cada vez mais compreender a beleza e suas manifestações, daí decorre a preocupação em se fazer uma história da arte da antiguidade. Somente no correlato material é que essas belezas, em última instância, inacessíveis, poderiam se manifestar. A história da 
arte para Winckelmann não seria uma narrativa, mas um "edifício doutrinário (Lehrgebäude)" e "seu principal fim é a essência da arte" (Winckelmann, 2009, p. XVI). Como a beleza é o fim último das artes esta obra fundadora deverá, e de um modo específico, tratar da beleza, mas não no sentido de uma metafísica da beleza:

A filosofia tem sido praticada e pensada principalmente por aqueles que lendo o trabalho de seus antecessores deixavam pouco espaço para a sensibilidade por sobre a qual foi aplicada uma pele dura. Nós fomos abandonados em um labirinto metafísico de sutilezas e palavrórios que serviu para gerar grandes livros e desagradar o entendimento. Por tal razão a arte foi, e ainda é, excluída da consideração filosófica; as verdades universais, que conduziriam de modo agradável à investigação da beleza, passaram por sobre a proximidade de sua fonte, não sendo aplicadas e explicadas por sua relação com as belezas particulares, perdendo-se em especulações sem nenhum ganho. (Winckelmann, 2009, pp. 239-241)

Portanto, ao que parece, é em sua História da arte da antiguidade que uma tentativa de dar conta da beleza em suas particularidades teria lugar. E neste trajeto a filosofia até poderia auxiliar, mas não esgotar as questões. A história surge como uma estética, ou ainda, podemos dizer que temos nela uma estética em forma de história, onde toda sorte de especulação será permitida: 
Eu me deixei levar para fora dos limites da história da arte. (...). Ao narrar o destino da arte não pude deixar de lançar meus olhos tão longe quanto me foi possível, assim como da costa a enamorada lança seus olhos envoltos em lágrimas ao mar vendo afastar-se seu amado e sem esperança de revê-lo. Ela até mesmo chega a acreditar ver na vela distante a imagem dele. Nós, como a enamorada, ficamos apenas com uma silhueta, que nos remete àquilo que era o objeto de nosso querer; mas tão grande é a falta que sentimos daquilo que perdemos que consideramos as cópias dos originais com maior atenção do que se estivéssemos em plena posse deles. Acontece aqui como com as pessoas que pretendem entender de fantasmas: acreditam vê-los onde não há nada. (Ibid., p. 839)

Essa tentativa de abarcar historicamente a beleza, ainda que de modo indireto, leva o dessa História autor a se deparar o tempo todo com a inabarcabilidade de sua tarefa. Já desde o prefácio de Pensamentos sobre a imitação dos gregos na pintura e na escultura Winckelmann parece ter plena consciência de que sua tarefa não teria fim: "O pouco que trago aqui é como que uma oferenda ao deus que protege o reino das artes, reino qual ousei pôr os pés. E os sacrifícios são menos em si mesmos do que na pureza de sua intenção e esta falará por mim." ( $I d ., 2002$, p. 28).

E essa intenção é a de abarcar as artes a partir da sensibilidade, mas também a de entender os fundamentos da beleza que são postos objetivamente nas obras. É claro que tal tarefa não se encerraria nunca. A pureza das intenções é a pureza de 
preencher espiritualmente a distância que nos separa dos antigos, é a intenção de sentir a Grécia como um grego e de poder transmiti-la. Essa tarefa nunca se colocou de modo pleno. Ela se estabelece na pureza das intenções e se vê o tempo todo diante do sem fim que já se encontra nas primeiras linhas de seu primeiro trabalho publicado. Winckelmann tinha consciência do sem fim de sua empreitada, interrompida por seu trágico assassinato em Trieste em 1768. Mas mesmo que ele tivesse vivido uma eternidade sua tarefa não se encerraria; e,no parágrafo que encerra sua obra maestra, a História da arte da antiguidade, ele nos indica a consciência desta infinitude e incompletude impostas pela grandeza inesgotável de sua tarefa:

O nome antiguidade tornou-se um pré-julgamento, mas um pré-julgamento como este não é isento de aplicações. Se propõe buscar muito, muito buscaremos e conseguiremos ver alguma coisa. Fossem os antigos mais precários teriam escrito mais e melhor sobre as artes. Em relação a eles somos como herdeiros insatisfeitos, mas movemos cada pedra e, por meio de conclusões sobre muitas singularidades, podemos ter alguma segurança conjectural que nos pode ensinar mais do que as notícias que nos deixaram os antigos; estas, afora algumas indicações que demonstram sua perspicácia, são meramente históricas. Não devemos nos intimidar na busca da verdade, ainda que isso gere prejuízo à nossa reputação. Alguém tem de errar para que muitos possam acertar. (id., 2009, p. 839)

Essa passagem, que numa primeira e desatenta leitura frustra 
o leitor que percorreu o todo desta obra monumental, marca a eterna busca de Winckelmann em relação à beleza e aos antigos, posto que esses são quase que correlatos: "arrazoar sobre a arte do desenho entre os gregos é o mesmo que tratar da beleza em todas as suas partes, pois esta foi a base e o fim de sua arte" (id., 2010, p. 63). No caminho em direção a este pensamento acerca da Grécia ficou claro que a tarefa não se encerraria em uma vida. Os gregos, que retiraram a beleza de sua incorporeidade e a expressaram na matéria, se colocam de modo tão distante que uma recepção plena de suas obras se coloca como uma tarefa interminável. O esforço hercúleo de Winckelmann se faz perceber de dois modos, o da maneira velada da própria beleza, "que pode até ser reduzida a alguns princípios, mas não se pode definir" (Ibid., p. 64), e o da ausência material das obras da antiguidade. Por meio de suas intuições Winckelmann busca suprimir este vazio e a tarefa nunca se verá encerrada. Ao fazer uma história em forma de estética, ou uma estética em forma de história, nosso autor marcou de modo indelével essas duas disciplinas em seu nascedouro. Tinha plena consciência do interminável de sua tarefa, e talvez por isso, em um caderno que carregava consigo, cheio de frases esparsas de vários autores antigos, chamado Collectanea zu meinen Leben, Winckelmann colocou como primeiro ítem a seguinte passagem da Política de Aristóteles: "Como se diz, o começo é a metade do todo" ( $O p$. cit. V, 4, 1303b 30 e Winckelmann, 1957, p. 154)

O seu esforço não foi o de encerrar uma atividade, sua ousadia foi a de por os pés em um reino nunca explorado. O sem fim da tarefa de Winckelmann é o sem fim de um explorador de terras novas. Um reino único e protegido por um só deus que se via ainda sem as fronteiras que viriam a se formar entre 
três disciplinas emergentes: a estética, a história da arte e a arqueologia. Munido apenas da grandeza pura de suas intenções e de seus sentidos afiados, sua história e seu modo de ver as artes marcam o começo de algo novo. A tarefa de compreender, quer os antigos, quer a beleza, não se encerraria nunca. Vemo-nos diante de uma obra que não encerra um mundo, mas que faz nascer um novo mundo, se consideramos que o começo é mesmo a metade do todo, A história da arte da antiguidade é uma metade de um esforço que não se vê encerrado até os nossos dias.

Estamos diante do tipo de esforço que bem descreveu Goethe: "Encontra-se nele [em Winckelmann] por vezes certo tateio, mas o que é grandioso é que seu tatear sempre nos leva a algo. Ele é comparável a Colombo, que quando ainda não havia encontrado o novo mundo, já o trazia em sua sensibilidade." (Eckermann, 1999, p. 235). E foi essa mesma sensibilidade que levou nosso autor à sua tarefa sem fim. Como Colombo, Winckelmann tocou novas terras, mas não as pôde explorar como um todo. Seu sem fim é o sem fim de todos que se aprofundaram no abismo que nos separa dos antigos, no campo da compreensão da beleza e de sua história. Podemos dizer que ainda somos pontos da linha que nunca termina que se inicia em um ponto chamado Winckelmann. E, assim, - para encerrar como começamos, dando a palavra mais uma vez a Goethe - "o eficiente mestre desperta obedientes discípulos e sua atividade se ramifica novamente até o infinito" (Goethe, 1969, p. 224). 


\section{Referências bibliográficas}

ECKERMANN. Gespräche mit Goethe. Frankfurt am Main: Deutscher Klassiker Verlag, 1999.

GOETHE, J. W. Escritos sobre literatura. Trad. e org.: Pedro Sussekind. Rio de Janeiro: 7 letras, 2000.

___. Winckelmann und sein Jahrhundert, Leipzig: Veb Seemann Verlag, 1969.

KANT, I. Crítica da razão pura. Trad. Manuela Pinto dos Santos e Alexandre Morujão. Liboa: Fundação Calouste Gulbenkian, 1997.

PATER, W. O renascimento. Trad. Jorge Henrique Bastos. São Paulo: Iluminuras, 2014.

POMMIER, E. Winckelmann, inventeur de l'histoire de l'art. Paris: Gallimard, 2003.

SCHILLER, F. Sobre a poesia ingênua e sentimental. Trad. Marcio Suzuki. São Paulo: Iluminuras, 1991.

SCHLEGEL, F. Dialeto dos Fragmentos. Trad. e org.: Marcio Suzuki. São Paulo: Iluminuras, 1997.

SUZUKI, M. O gênio romântico. São Paulo, Iluminuras, 1998.

TESTA, F. Winckemann e l'invenzione della storia dell'arte. Bologna: Minerva Edizioni, 1999.

WINCKELMANN, J. J. Briefe, 4v. Walter Rehm (org.). Berlin: Walter de Gruyter, 1952-1957. . Statuen Beschreibungen; in Frühklassizismus - Position und Opposition: Winckelmann, Mengs, Heinse, Bibliothek der Kunstliteratur, v.2. Frankfurt am Main: Deutscher Klassiker Verlag, 1995.

- Geschichte der Kunst des Alterthums - Erste Auflage Dresden 1764 - Zweite Auflage Wien 1776. Mainz am Rhein: Verlag Philpp von Zabern, 2009. 
- Kleine Schriften, Vorreden, Entwürfe. Walter Rehm (org.). Berlin: Walter de Gruyter, 2002.

Monumenti antichi inediti. Mainz am Rhein: Verlag Philpp von Zabern, 2010.

- Reflexiones sobre la imitación de las obras gregas em la pintura y la escultura. Trad. Antonio Mas. Cidade do México: Fondo de cultura económica, 2007. 